\title{
Post-punching mechanism of slab-column joints subjected upward and downward punching shear actions
}

\author{
Mengzhu Diao, ${ }^{1}$ Yi Li, Ph.D., ${ }^{2}$ Xinzheng Lu, Ph.D., ${ }^{3}$, Hong Guan, Ph.D., ${ }^{4}$ \\ and Fangfang Liu ${ }^{5}$ \\ ${ }^{1}$ Department of Civil Engineering, Beijing University of Technology, Beijing \\ 100124, China; e-mail: mengzhu.diao@griffithuni.edu.au \\ ${ }^{2}$ Department of Civil Engineering, Beijing University of Technology, Beijing \\ 100124, China; e-mail: yili@bjut.edu.cn \\ ${ }^{3}$ Department of Civil Engineering, Tsinghua University, Beijing 100084, China; e- \\ mail: luxz@tsinghua.edu.cn \\ ${ }^{4}$ Griffith School of Engineering, Griffith University Gold Coast Campus, \\ Queensland 4222, Australia; e-mail: h.guan@griffith.edu.au \\ ${ }^{5}$ Department of Civil Engineering, Beijing University of Technology, Beijing \\ 100124, China; e-mail: 18801495113@emails.bjut.edu.cn
}

\begin{abstract}
In flat plate structures, the slab-column joints are prone to punching shear failure, which would trigger progressive collapse of the entire structural systems. The joints subjected upward punching shear (UPS) and downward punching shear (DPS) actions exhibit different post-punching behavior, which will affect the progressive collapse of flat plate structures. A static collapse test was conducted on two slabcolumn joint specimens (UPS-1 and DPS-1). The structural resistance and deformation were analyzed to explore the collapse-resistant mechanism of the joints after punching shear. The test results illustrate that the post-punching bearing and deformation capacities are governed by the through column longitudinal reinforcement (including both integrity reinforcement (IR) and flexural reinforcement (FR)) in the slab. The longitudinal bars ruptured in reverse orders under UPS and DPS failure scenarios. In DPS-1, the peak resistance under the suspension mechanism was reached when the first FR bar ruptured while the IR bars remained intact. The peak resistance of UPS-1, on the other hand, was achieved at the onset of the IR bars being ruptured and the FR bars being detached from the concrete.
\end{abstract}

Keyword: slab-column joint; post-punching behaviour; progressive collapse; upward punching shear; downward punching shear; experimental test 


\section{INTRODUCTION}

Progressive collapse is defined as the spread of an initial local failure from elements to elements, which eventually results in the collapse of an entire structure or disproportionately large part of it (ASCE 2010). Progressive collapse can cause severe loss of life and property leading to an adverse social impact. Current studies (Yu and Tan 2017, Lu et al. 2016) and design regulations (GSA 2013, DOD 2013, CECS 2014) on progressive collapse are mainly focused on the most popular and ductile-deformation dominant steel and concrete frames; studies on other forms of constructions are comparatively limited. Compared to the frame structures, the ductility and bearing capacity of reinforced concrete (RC) flat-slab structures are relatively low. The slab-column joints are especially prone to brittle punching shear failure, thus the risk of progressive collapse triggered by such localized failure is higher (Hawkins and Mitchell 1979). Collapses of the Boston federal avenue apartment in 1971, the Sampoong department store in 1995 and the Swiss Solothurn garage in 2004 are typical progressive collapse events of RC flat plate systems (King and Delatte 2004, Gardner et al. 2002, Muttoni et al. 2008).

Figure 1demonstrates two types of potential punching shear failure modes of a flat-slab structure: 1) upward punching shear (referred to as UPS) failure showing an inverted conical damage pattern, which is caused by overloading of the slab directly or indirectly through the redistribution of the internal forces of the slab during the process of collapse; 2) downward punching shear (referred to as DPS) failure in form of a cone shape, which is usually triggered by an uplifting action to the slabs, likely generated from blast or hurricane (Dusenberry 2010, Robertson et al. 2007).

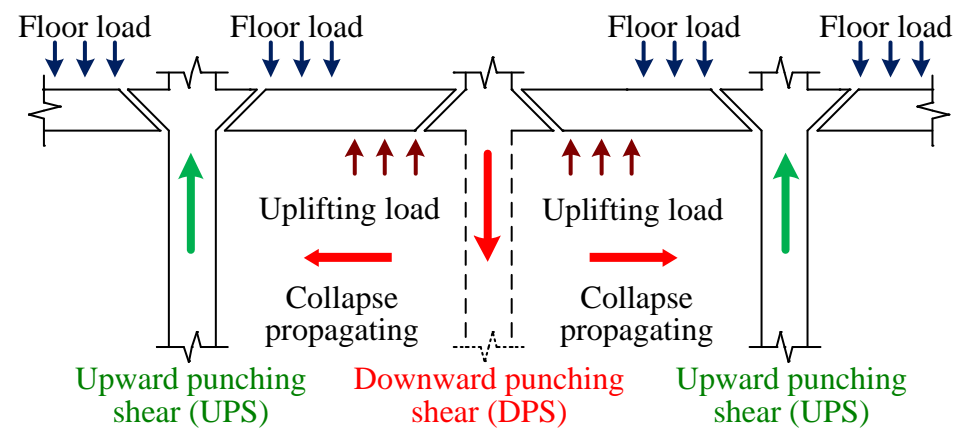

Figure 1. Failure modeses of slab-column joints in progressive collapse

In order to gain in-depth understanding of the collapse-resistant behaviour of 
RC flat plate structures, a static collapse test was conducted on two slab-column joint specimens with missing columns, designated as UPS-1 and DPS-1. The specimens were tested under displacement-control scheme by adding downward monolithic load to the top of the column stub. Damage and failure modes of the specimens under large deformations were examined, by which the progressive collapse mechanism of the specimens was explored.

\section{EXPERIMENTAL PROGRAM}

\section{Design of the specimens}

A 3-storey $4 \times 4$ bay flat plate structure was designed in accordance with the Australian building code (SAC 2009). Figure 2 provides the plan view of the prototype structure and test setup. Two 1/3 scaled slab-column joint specimens (UPS-1 and DPS-1) taken from the ground floor of the prototype structure, were cast and tested (see Figure 3). The boundary of the joint is denoted by the line of contraflexure (Figure 2a). For UPS-1, the specimen was tested upside down under a downward loading, which is similar to an existing experiment (Ruiz et al. 2013). For DPS-1, the specimen was tested upright subjected to a downward loading. In order to achieve the downward loading pattern, the flexural reinforcement (FR) and integrity reinforcement (IR) of DPS-1 were arranged at the top and bottom of the slabs, respectively (Figure 3c), and the FR and IR bars were interchangeably placed in UPS-1 (Figure 3d). Note that the IR bars in UPS-1 were also bent down at the slab-boundary beam interface (Figure 3d) to release the rotational restraint at the onset of tensile cracks in the top concrete cover. In addition, the horizontal restraint and the rotational release at the contraflexural point can be properly simulated.

The reinforcement details in the slabs for both specimens were shown in Figure 3. The material properties of the reinforcement and concrete are summarised in Table 1.
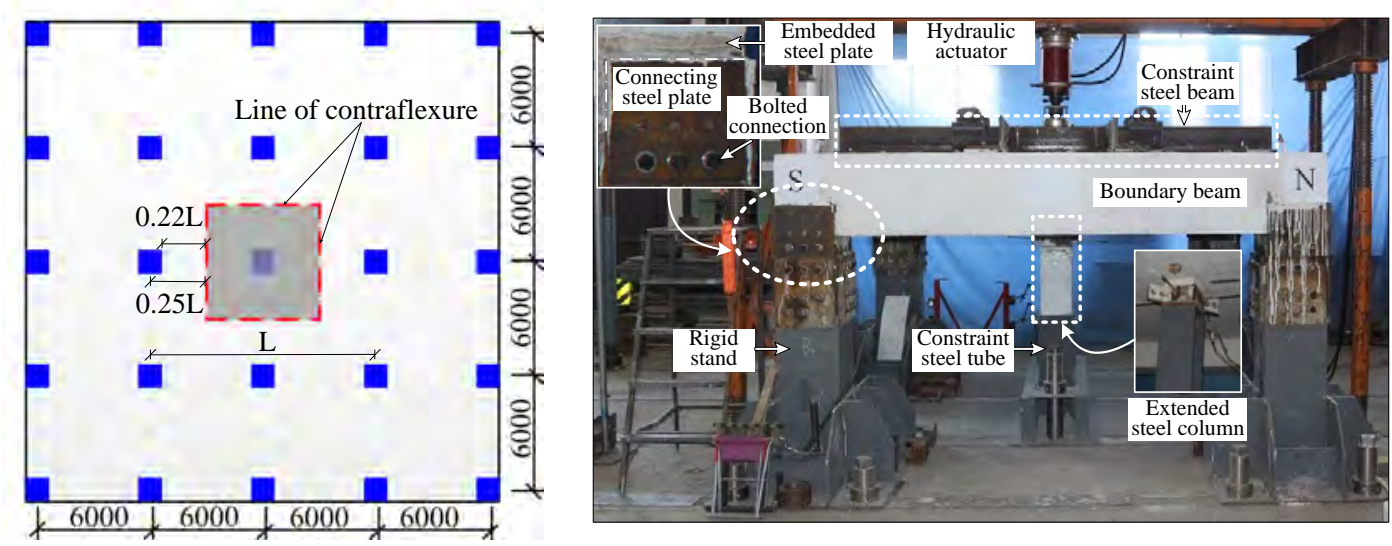
(a) Plan view of prototype

(b) Test setup

structure

Figure 2. Prototype structure and test setup (unit: mm)

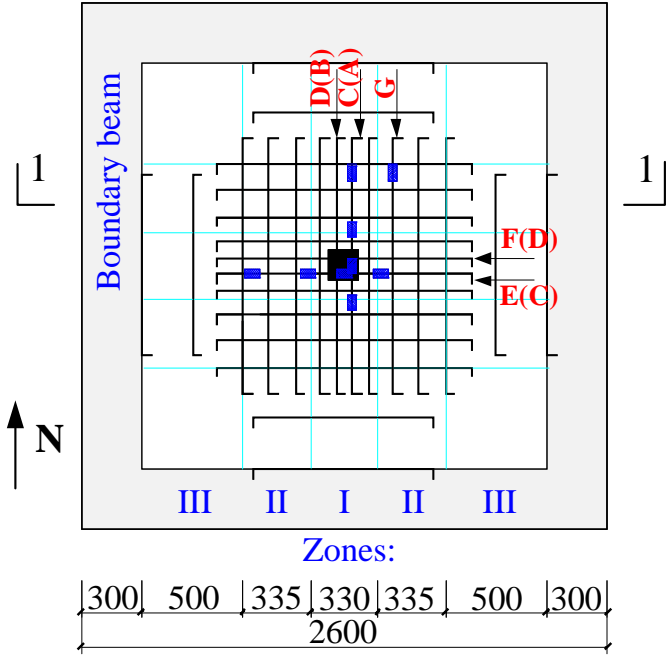

Note: $\mathrm{D} / \mathrm{C} / \mathrm{G} / \mathrm{F} / \mathrm{E}$ represents rebar in UPS-1;

$\mathrm{B} / \mathrm{A} / \mathrm{D} / \mathrm{C}$ in parenthesis represents rebar in DPS-1.

(a) Flexural reinforcement (FR)

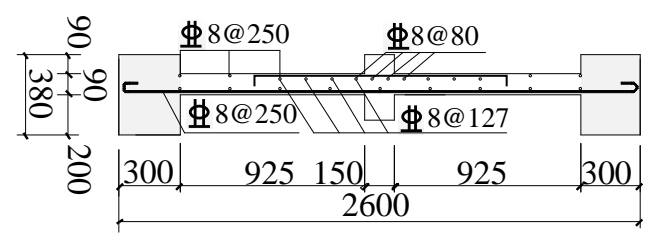

(c) DPS-1
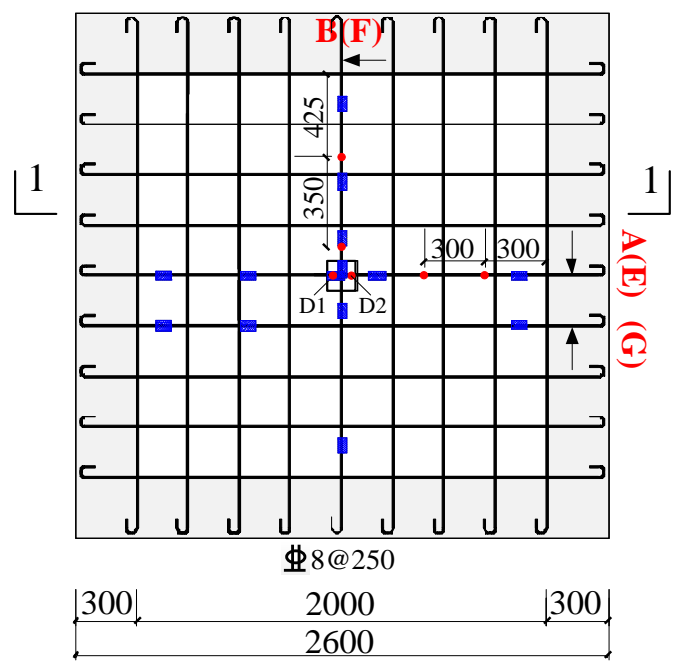

Note: B/A represents rebar in UPS-1; $\mathrm{F} / \mathrm{E} / \mathrm{G}$ in parenthesis represents rebar in DPS-1.

(b) Integrity reinforcement (IR)

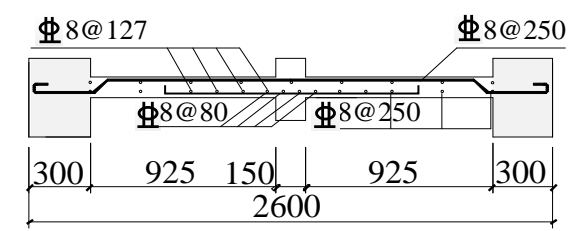

(d) UPS-1

Figure 3. Reinforcement in DPS-1 and UPS-1 (unit: mm)

Note: (1) m represents steel strain gauge, • represents LVDT;

(2) Details of reinforcement in Zones I to III are given in Table 1. Zones I and II denote the column strip and Zone III represents the middle strip.

Table 1 .Material properties

\begin{tabular}{|c|c|c|c|c|c|}
\hline Tyре & $\begin{array}{c}\text { Yield } \\
\text { strength } \\
f_{\mathrm{y}} / \mathrm{MPa}\end{array}$ & $\begin{array}{l}\text { Ultimate } \\
\text { strength } \\
f_{\mathrm{u}} / \mathrm{MPa}\end{array}$ & $\begin{array}{c}\text { Elastic } \\
\text { modulus } \\
E_{\mathrm{s}} / \mathrm{GPa}\end{array}$ & $\begin{array}{c}\text { Ratio of } \\
\text { elongation } \\
e / \% \\
\end{array}$ & $\begin{array}{c}\text { Cubic compressive } \\
\text { strength of concrete } \\
f_{\mathrm{c}} / \mathrm{MPa}\end{array}$ \\
\hline$\phi 8$ & 298 & 471 & \multirow{3}{*}{205} & 29 & \multirow{3}{*}{31} \\
\hline$\$ 8$ & 436 & 643 & & 24 & \\
\hline$\$ 12$ & 511 & 608 & & 15 & \\
\hline
\end{tabular}




\section{Test setup and instrumentation}

Referring to an existing progressive collapse test (Yi et al. 2008), the quasi-static pushdown loading method was used and a downward displacement was applied to the top of the column stub. The lower part of the column stub was bolt connected to a short steel column (see Figure 2b), which was then inserted into a steel tube fixed to the ground to restrict the stub moving in the vertical direction only. Four pairs of steel plates were also embedded in the top surface of each boundary beam, enabling connection with a hash-shaped steel beam, which can provide sufficient horizontal restraint for the specimen. The experimental results showed that the horizontal displacements of the boundary beams were less than $2 \mathrm{~mm}(1 / 1000$ of the span), confirming the effectiveness of inclusion of the boundary beams and hash-shaped steel beam.

\section{EXPERIMENTAL PHNOMENA AND FAILURE MECHANESIMS}

The load-displacement curves of UPS-1 and DPS-1 are shown in Figure 4 (recorded by LVDTs D1, D2 in Figure 3b). The load-displacement responses can be divided into three stages: flexural stage, punching failure stage and suspension stage. Five key points are highlighted, including the punching failure point $\left(F_{\mathrm{p}}, \Delta_{\mathrm{p}}\right)$, the load mechanism transition point $\left(F_{\mathrm{t}}, \Delta \mathrm{t}\right)$ and three critical points in the suspension stage $\left(F_{s i}, \Delta_{s i}, i=1,2,3\right)$ corresponding to the steel bars either ruptured and/or being pulled out. Note that the variation of the stiffness of the loaddisplacement curve can be defined by the slope of the curve symbolised as $K$.

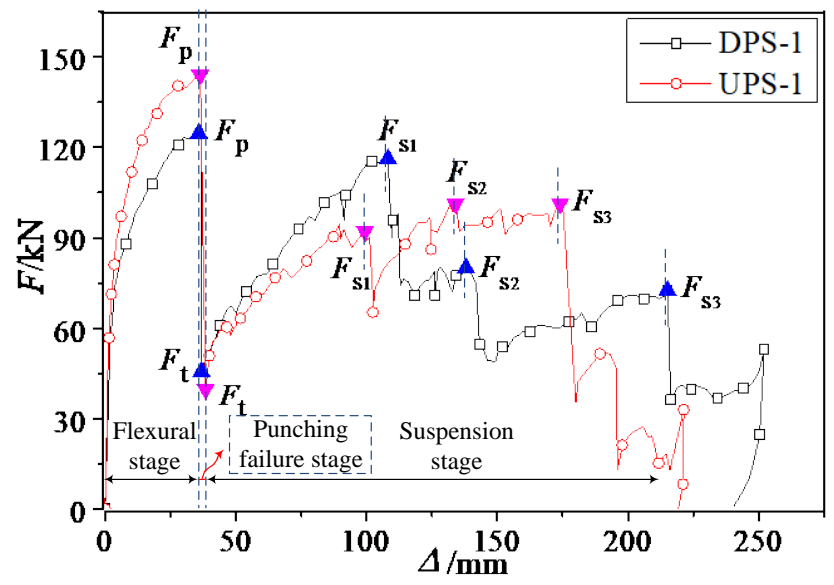

Figure 4. Load-displacement curves of DPS-1 and UPS-1

\section{Flexural and punching failure mechanisms}


In the flexural stage, the applied load was resisted by the specimens through bending actions. When punching shear failure occurred, the specimens reached their respective peak loads $F_{\mathrm{p}}$. DPS-1 demonstrated to have a smaller bending capacity $\left(F_{\mathrm{p}}=124 \mathrm{kN}\right)$, which is $16 \%$ lower than that of UPS-1 $\left(F_{\mathrm{p}}=144 \mathrm{kN}\right)$ as its number of the bottom reinforcement was much less than that in UPS-1 (see Figure 4). However, the values of $\Delta_{\mathrm{p}}$ for the two specimens were very close owing to their identical geometric, material and boundary conditions.

The punching cracks then propagated throughout the whole thickness of the slabs. This led to a significant loss of the bending capacity in DPS-1 (i.e., $79 \mathrm{kN}$ reduction from $F_{\mathrm{p}}$ to $F_{\mathrm{t}}$ ) and UPS-1 (i.e.,104 $\mathrm{kN}$ reduction). The values of $F_{\mathrm{t}}$ for both $\left(F_{\mathrm{t}}=45 \mathrm{kN}\right.$ in DPS- 1 and $F_{\mathrm{t}}=40 \mathrm{kN}$ in UPS-1) were almost the same due to the identical numbers of slab reinforcement in these two specimens.

\section{Post-punching failure mechanism}

After the occurrence of punching failure, the entire cross-section of the slab was in tension and the concrete merely acted as an anchor to the reinforcement. The suspension stage can also be divided into three sub-stages, i.e. the three critical points $\left(F_{s i}, i=1,2,3\right)$ marked in Figure 4 . Detailed discussions are given below in conjunction with the post-punching failure mechanisms and damage modes illustrated in Figures 5 and 6.

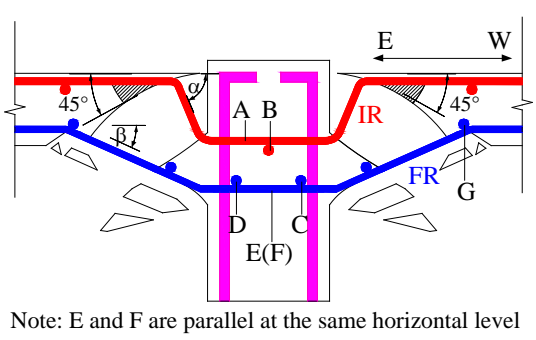

(a) UPS-1

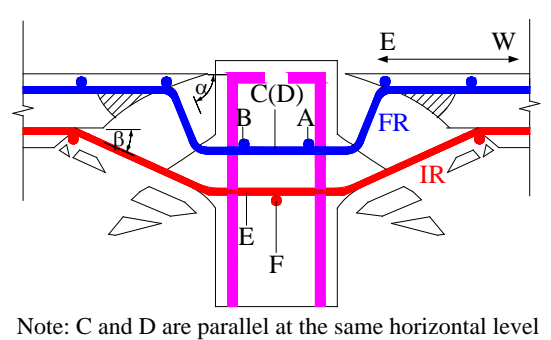

(b) DPS-1

Figure 5. Post-punching mechanisms of specimens

(Note: shaded area denotes concrete support to reinforcement)

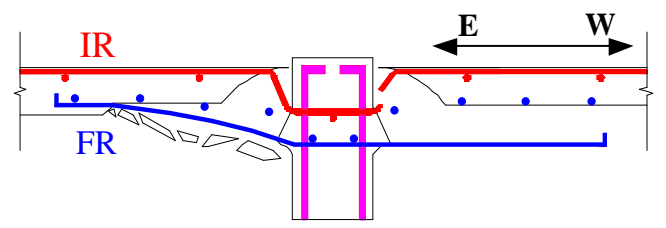

(a) UPS-1: FR bars pulled out and detached from slab soffit

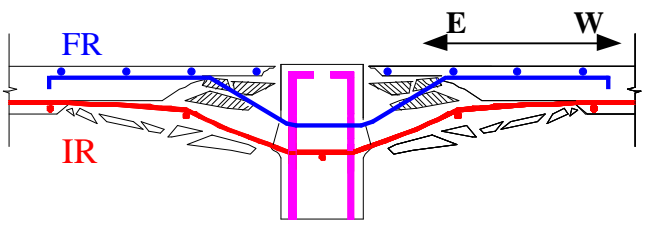

(b) DPS-1: IR bars pulled out and concrete core damaged in shear

Figure 6. Final damage modes in UPS-1 and DPS-1 
1) In the first sub-stage (from $F_{t}$ to $F_{s 1}$, Figure $4 a$ ), the contribution of the FR and IR bars going through the column region was greater, due to their larger deformations, than that of the other bars elsewhere. Quantitative evidence is presented in Figure 7a, for instance, the strain values of rebar E in DPS-1(10094 $\mu \varepsilon)$ and rebar C in UPS-1(8708 $\mu \varepsilon)$ corresponding to the load level $F_{\mathrm{s} 1}$ are 1.6 times and 4.2 times larger than $6305 \mu \varepsilon$ and $2081 \mu \varepsilon$ of rebar G (in the vicinity of the column) in DPS-1 and UPS-1, respectively.

As seen in Figure $5 \mathrm{a}$, the bend down angle of the top rebar $\left(\alpha=86^{\circ}\right)$ in UPS-1 due to punching was much greater than that of the bottom rebar $\left(\beta=50^{\circ}\right)$, which caused larger value of the strain and the vertical component of the axial force in the top reinforcement than those in the bottom reinforcement. Similar phenomenon can be observed in DPS-1. This implies that the bearing capacity was predominantly contributed by the top reinforcement in the column region. Note further that in DPS-1, four (A, B, C, D) and two (E, F) rebars were located in the top and bottom of the slab, respectively (Figure $5 b$ ), and these rebars were inversely positioned in UPS-1 (Figure 5a). Therefore, DPS-1 was able to develop a 15\% higher stiffness $K$ in this sub-stage than that developed by UPS-1 in the beginning of this sub-stage (Figure 4).

The top reinforcement shown in Figures 3a and 3b, i.e., FR bars in DPS-1, were only embedded in the slab whilst IR bars in UPS-1 were fully anchored into the boundary beams. Such an anchorage has resulted in a lower level of strain being developed in rebar A in DPS-1 $(3786 \mu \varepsilon)$ for instance, which is only $26 \%$ of that developed in UPS-1 $(14709 \mu \varepsilon)$ (Figure $7 \mathrm{~b}$ ), leading to the top reinforcement in DPS-1 being ruptured at a larger displacement than that in UPS-1. Additionally, due to the larger $K$ in DPS-1, the load carrying capacity $F_{\mathrm{s} 1}$ in DPS-1 (i.e., $F_{\mathrm{s} 1}=$ $116 \mathrm{kN})$ was $22 \%$ higher than that in UPS-1 $\left(F_{\mathrm{s} 1}=95 \mathrm{kN}\right)$ (Figure 4). The end of this stage is marked by the rupture of top reinforcement, viz. rebar A in UPS-1 and rebars A and B in DPS-1.

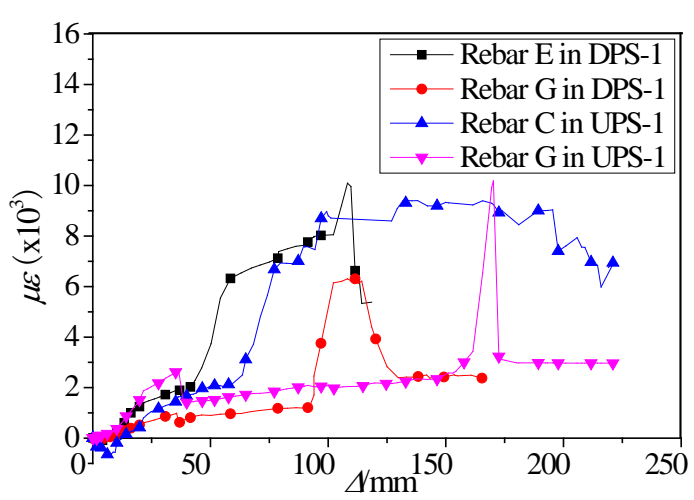

(a) Bottom slab reinforcement

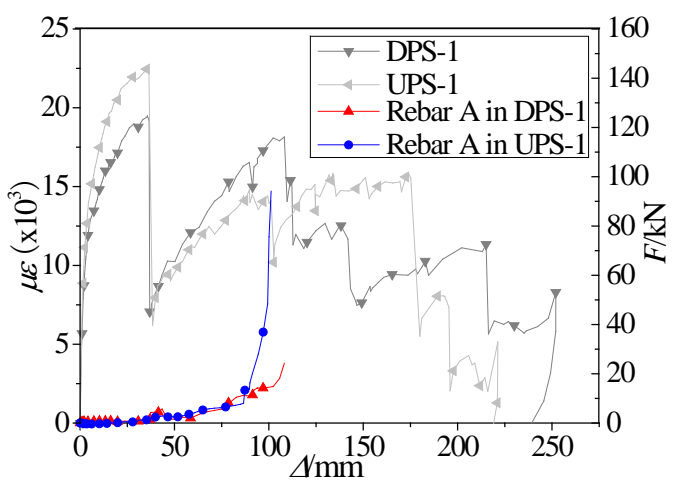

(b) Top slab reinforcement 
Figure 7. Strain development of slab reinforcement in DPS-1 and UPS-1

2) In the second sub-stage (from $F_{\mathrm{s} 1}$ to $F_{\mathrm{s} 2}$, Figure 4a), the applied load was largely resisted by the upper layer of bottom reinforcement going through the column (rebars C and D in UPS-1 and rebar E in DPS-1), as shown in Figures 5. This is because upon rupture of the upper layer of the top reinforcement (rebar A in UPS-1, rebars A and B in DPS-1), restrains were subsequently released from these upper layer rebars to their lower layer counterparts (rebar B in UPS-1, rebars C and $\mathrm{D}$ in DPS-1). This in turn decelerated the strain development in these lower layer rebars and therefore their rupture was delayed. This is reflected in Figure 8 where, in DPS-1 for instance, the strain value of rebar C decreased upon rupture of rebar A.

With respect to the concrete behaviour during this sub-stage, the concrete core bounded by the punching shear failure surface was compressed by the excessively deformed reinforcement in this region (shaded areas in Figures 5). Due to opposite punching directions, UPS-1 exhibited that only one bottom reinforcement, FR bar (rebar E), was completely detached from the slab soffit (Figure 6a), thereby causing little change in the bearing capacity (note the small drop of the peak bearing capacity $F_{\mathrm{s} 2}$ in Figure 4). For DPS-1, on the contrary, the concrete core was more heavily compressed due to the larger number of top reinforcement and the bottom reinforcement was only partially pulled out from the concrete (Figure 6b).

3 ) In the third sub-stage (from $F_{\mathrm{s} 2}$ to $F_{\mathrm{s} 3}$, Figure $4 \mathrm{a}$ ), for UPS-1, although the lower layer of its bottom reinforcement, rebar E, was detached from the slab soffit, its upper layer rebars (i.e. rebar $\mathrm{C}$ ) continued to provide bearing resistance due to the anchorage provided by the concrete. This can be confirmed in Figure 9 where the strain of rebar $\mathrm{C}$ was much greater than that in rebar $\mathrm{E}$ at $\Delta_{\mathrm{s} 2}$. For DPS-1, although not being presented herein, the strain measurements of the two bottom rebars, i.e. rebar E from $1107 \mu \varepsilon$ at $\Delta_{\mathrm{s} 2}$ to $3777 \mu \varepsilon$ at $\Delta_{\mathrm{s} 3}$ and rebar $\mathrm{F}$ from $660 \mu \varepsilon$ to $1915 \mu \varepsilon$ indicated their major contribution to the load bearing during this sub-stage.

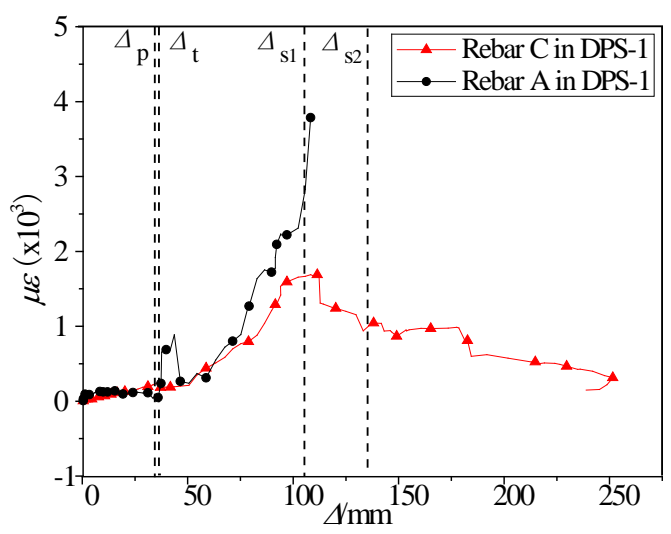

Figure 8. The strain of top slab reinforcement in DPS-1

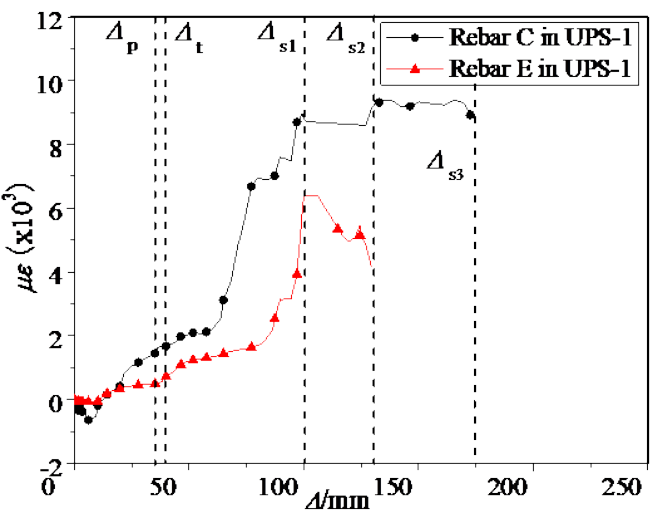

Figure 9. The bottom slab reinforcement strain of UPS-1 


\section{CONCLUSION}

This study experimentally investigated the mechanical performance of two slabcolumn joint specimens under different punching directions, in which the postpunching behaviour and the resistant capacity were highlighted. The following conclusions are drawn from the test results:

(1) The punching shear capacity of DPS-1 was $16 \%$ smaller due to its smaller number of bottom slab bars. However, the punching deformations of DPS-1 and UPS-1 were similar owing to their identical geometric, material and boundary conditions.

(2) After punching occurred, the post-punching bearing and deformation capacities of flat slab-column joints are dominantly determined by reinforcement going through the column. UPS-1 reached its peak bearing capacity in the suspension stage when one IR bar has already ruptured and one FR bar was detached from the concrete in the slab soffit. The peak resistance of DPS-1 after punching shear was reached when one of the FR bars ruptured while the IR bars remained intact.

(3) The specimens exhibited relatively higher post-punching resistance in the first sub-stage, which could be applied as a second defence mechanism for the collapse-resist design of flat plate structures. In this sub-stage, DPS-1 was able to develop a $15 \%$ higher stiffness and a $22 \%$ higher load carrying capacity in comparison to that in UPS-1.

\section{ACKNOWLEDGMENTS}

The authors are grateful for the financial support received from the National Key Research and Development Program of China (No. 2016YFC0701400), the National Natural Science Foundation of China (No. 51578018), the Beijing Nova Program (No. xx2017093) and the Australian Research Council through an ARC Discovery Project (DP150100606).

\section{REFERENCES}

American Society of Civil Engineers (ASCE). (2010). Minimum design loads for buildings and other structures, ASCE7-10. Reston (VA).

China Engineering Construction Standardization Association (CECS). (2010). Code for Anti-collapse Design of Building, CECS392:2014. Beijing.

Dusenberry, D. O. (2010). Handbook for Blast-resistant Design of Buildings. John Wiley \& Sons, Inc.

Department of Defense (DoD). (2013) Design of Structures to Resist Progressive Collapse,UFC 4-023-03. Washington (DC). 
Gardner, N. J., Huh, J., and Chung, L. (2002). "Lessons from the Sampoong Department Store Collapse.” Cement Concrete Comp. 24: 523-529.

General Service Administration (GSA). (2013). Alternate Path Analysis \& Design Guidelines for Progressive Collapse Resistance. Washington (DC).

Hawkins, N. M. and Mitchell, D. (1979). "Progressive Collapse of Flat Plate Structures.” ACI Struct. J. 76(7), 775-808.

King, S. and Delatte, N. (2004). "Collapse of 2000 Commonwealth Avenue: Punching Shear Case Study.” J Perform. Constr. Fac., 18(1), 54-61.

Lu, X. Z., Lin, K. Q., Li, Y., Guan, H., Ren, P. Q., and Zhou, Y. L.. (2011). "Experimental Investigation of RC Beam-Slab Substructures against Progressive Collapse Subject to An Edge-Column-Removal Scenario.” Eng. Struct. 149, 91-103.

Muttoni, A., Ruiz, M. F., Fürst, A., Guandalini, S., Hunkeler, F., Moser, K., and Seiler. H. (2008). Structural Safety of Parking Garages. Documentation D 0226 SIA, Swiss Society of Engineers and Architects, Zürich.

Ruiz, M. F., Muttoni, A., and Kunz, J. (2010). "Strengthening of Flat Slabs against Punching Shear using Post-installed Shear Reinforcement.” ACI Struct. J. 107(4), 434-442.

Robertson, I. N., Riggs, H. R., Yim, S. C., and Young, Y. L. (2007). "Lessons from Hurricane Katrina Storm Surge on Bridges and Buildings.” J. Waterw. Port CASCE, 133(6), 463-483.

Standards Australia Committee (SAC) BD-002. (2009) Concrete Structures. AS3600-2009, Sydney.

Yi, W. J., He, Q. F., Xiao, Y., and Sashi, K. K. (2008). "Experimental Study on Progressive Collapse-Resistant Behavior of Reinforced Concrete Frame Structures.” ACI Struct. J., 105(4), 433-439.

Yu, J., and Tan, K. H. (2017). "Structural Behavior of Reinforced Concrete Frames Subjected to Progressive Collapse.” ACI Struct. J. 114(1), 63-74. 